Table 1. Number of examined knee joints with different anomalies according to WORMS (>=1 point).

\begin{tabular}{lccccc}
\hline Parameter & $\begin{array}{c}\text { MFTJ } \\
\text { (percent, total) }\end{array}$ & $\begin{array}{c}\text { LFTJ, } \\
\text { (percent, total) }\end{array}$ & $\begin{array}{c}\text { PFJ } \\
\text { (percent, total) }\end{array}$ & $\begin{array}{c}\text { S-region, } \\
\text { (percent, total) }\end{array}$ & $\begin{array}{c}\text { Total, } \\
\text { (percent, total) }\end{array}$ \\
\hline $\begin{array}{l}\text { Cartilage } \\
\text { Marrow }\end{array}$ & $19,44 \%(n=7)$ & $19,44 \%(n=7)$ & $75,00 \%(n=27)$ & - & $83,33 \%(n=30)$ \\
$\quad$ abnormality & $0,00 \%$ & $2,78 \%(n=1)$ & $0,00 \%$ & $13,89 \%(n=5)$ & $16,67 \%(n=6)$ \\
Bone cysts & $0,00 \%$ & $0,00 \%$ & $0,00 \%$ & $0,00 \%$ & $0,00 \%$ \\
Bone attrition & $66,67 \%(n=24)$ & $0,00 \%$ & - & - & $66,67 \%(n=24)$ \\
Osteophytes & $88,89 \%(n=32)$ & $86,11 \%(n=31)$ & $97,22 \%(n=35)$ & - & $100,00 \%(n=36)$ \\
Menisci & $0,00 \%$ & $2,78 \%(n=1)$ & - & - & $2,78 \%(n=1)$ \\
Ligaments & - & - & - & - & $0,00 \%$ \\
Synovitis & - & - & - & - & $33,33 \%(n=12)$ \\
Total & - & - & - & - & $100,00 \%(n=36)$ \\
& & & - & &
\end{tabular}

Besides, we calculated mean points in each parameter in the scale and compared it with the maximum score in this parameter (in percent). Table 2 shows the results. The most severe change was bone attrition.

Table 2. Mean points of different WORMS parameters in examined knee joints.

\begin{tabular}{lccccc}
\hline Parameter & $\begin{array}{c}\text { MFTJ } \\
\text { (percent, total) }\end{array}$ & $\begin{array}{c}\text { LFTJ, } \\
\text { (percent, total) }\end{array}$ & $\begin{array}{c}\text { PFJ } \\
\text { (percent, total) }\end{array}$ & $\begin{array}{c}\text { S-region, } \\
\text { (percent, total) }\end{array}$ & $\begin{array}{c}\text { Total, } \\
\text { (percent, total) }\end{array}$ \\
\hline Cartilage & $1,30 \%$ & $1,02 \%$ & $7,64 \%$ & - & $2,91 \%$ \\
Marrow & $0,00 \%$ & $0,37 \%$ & $0,00 \%$ & $4,63 \%$ & $0,31 \%$ \\
$\quad$ abnormality & & & & & \\
Bone cysts & $0,00 \%$ & $0,00 \%$ & $0,00 \%$ & $0,00 \%$ & $0,00 \%$ \\
Bone attrition & $15,37 \%$ & $0,00 \%$ & $0,00 \%$ & - & $1,75 \%$ \\
Osteophytes & $6,59 \%$ & $5,48 \%$ & $8,33 \%$ & - & $6,69 \%$ \\
Menisci & $0,00 \%$ & $0,93 \%$ & - & - & $0,46 \%$ \\
Ligaments & - & - & - & - & $0,00 \%$ \\
Synovitis & - & - & - & - & $12,04 \%$ \\
Total & - & - & - & - & $3,61 \%$ \\
\hline
\end{tabular}

We didn't observe asymptomatic lesions in the medial meniscus, marrow abnormality in MFTJ and LFTJ, subchondral cysts in any location, ligament lesions. Despite minimal osteophytes almost in all individuals, they didn't have any clinical features of knee OA.

Conclusion: MRI of the knee joints in the cohort of young relatively healthy individuals without clinical features of $O A$ revealed irreversible structural changes characteristic of symptomatic OA. There is no association between symptoms and structural damage. Based on these, we can make an assumption about asymptomatic stage of $\mathrm{OA}$. In order to distinguish between definitions of early asymptomatic OA as a disease onset and asymptomatic structural changes as reflection of metabolic disorders it is necessary to follow up and to perform an in-depth examination of these individuals.

References:

[1] Migliore, A., Scirè, C.A., Carmona, L. et al. The challenge of the definition of early symptomatic knee osteoarthritis: a proposal of criteria and red flags from an international initiative promoted by the Italian Society for Rheumatology. Rheumatol Int 37, 1227-1236 (2017).

Disclosure of Interests: Natalia Martusevich Shareholder of: k, Svetlana Duben: None declared, Alexander Aleshkevich: None declared, Alena Dmitrieva: None declared, Tatsiana Bondar: None declared, Katsiarina Gudkevich: None declared DOI: 10.1136/annrheumdis-2020-eular.6604

\section{FRI0387 A PROGNOSTIC MODEL OF PRE-RADIOGRAPHIC KNEE OSTEOARTHRITIS: DATA FROM THE OSTEOARTHRITIS INITIATIVE}

M. Camacho Encina ${ }^{1}$, V. Balboa-Barreiro ${ }^{1}$, I. Rego-Perez ${ }^{1}$, R. Paz González', V. Calamia', L. Lourido', C. Ruiz-Romero', F. J. Blanco' ${ }^{1}{ }^{1} I N I B I C$, Rheumatology Research Group, A Coruña, Spain

Background: The improvement of the existing diagnostic methods to detect pre-radiographic knee $\mathrm{OA}(\mathrm{KOA})$ may facilitate the development of preventive strategies. It has been postulated that combining biochemical with clinical markers, may increase the prognostic power to detect who is at high risk for developing KOA.

Objectives: To validate and qualify the ability of 6 proteins with biomarker potential to generate a prognostic model of knee OA prediction through the combination of validated OA biomarkers and clinical markers.

Methods: In the validation phase (Figure 1), 749 sera at the baseline visit belonging to participants from the Osteoarthritis Initiative (OAI) Cohort were randomly selected to blindly quantify 6 biomarkers using in-house custom sandwich microarrays built using the XMAP technology. Among these, only 540 participants have a Kellgren and Lawrence $(\mathrm{KL})$ grade $=0-1$ at the beginning of the OAI study in at least one knee. After a follow-up period of 96 months, 209 participants developed $\mathrm{KOA}$ in at least one knee $(\mathrm{KL} \geq 2)$ and were classified as incident group, whereas 331 did not developed the disease $(K L=0-1)$ and were classified as not-incident group. Statistical differences between the outcome groups were assessed by non-parametric Mann-Whitney $U$ tests. In the qualification phase $(n=540)$, univariate regression analyses were carried out to investigate whether the individual biomarkers were associated with the risk of KOA development. A clinical prognostic model was defined by stepwise regression analysis using clinical non-radiographic variables significantly associated with the OA incidence. The utility of the potential biomarkers, alone or in combination, was evaluated by comparing the Area Under the Curve (AUC) of the clinical prognostic model with the biomarkers plus clinical prognostic models. In addition, sen

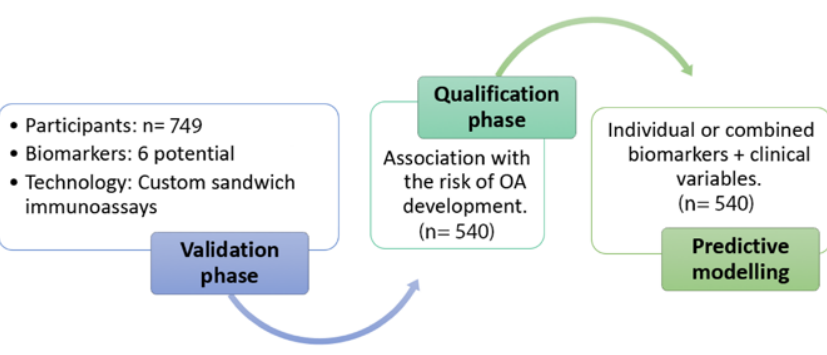

Figure 1. Study desing

Results: The incident group showed significant higher serum concentrations at the baseline visit $(p<0.05)$ for all the potential biomarkers analyzed in this study. Moreover, 5 of them were also significantly associated with the future appear ance of radiographic KOA, yielding Odds Ratios $(\mathrm{OR}) \geq 10 \mathrm{per} 10 \mu \mathrm{g} / \mathrm{ml}$ increase. Among all the possible combinations, the inclusion of 2 biomarkers to the clinical prognostic model showed a significant improvement of the predictive capacity (AUCs $=0.78$ vs $0.82, p=0,044)$ with $65 \%(95 \%$ Confidence Interval $(95 \% \mathrm{Cl})$ : $60-70 \%)$ specificity and $88 \%(95 \% \mathrm{Cl}: 81-91 \%)$ sensitivity. Variables included in the regression model and all metrics comparing the biomarkers plus clinical prognostic model with the clinical prognostic model are shown in Figure 2A. The ROC curves of the biomarkers-only model, clinical prognostic model and biomarkers plus clinical prognostic model are represented in Figure 2B.
$\mathbf{A}$

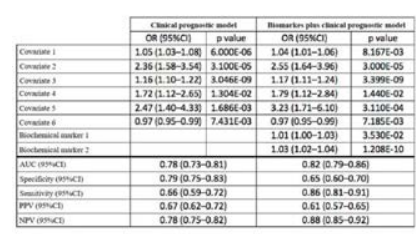

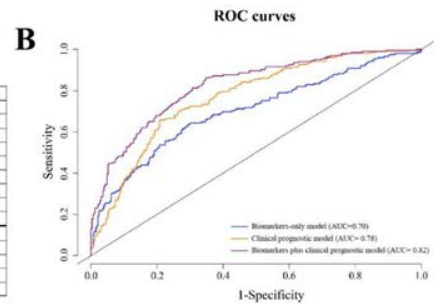

B
Figure 2. (A) Multivariate regression analysis (B) ROC curves of the models

Conclusion: We have generated a prognostic model for the prediction of KOA by combining biomarkers and clinical variables, which showed a putative utility in the clinical setting by improving the predictive capacity of a clinical prognostic model to identify patients at a higher risk to develop radiographic KOA.

Disclosure of Interests: Maria Camacho Encina: None declared, Vanesa Balboa-Barreiro: None declared, Ignacio Rego-Perez: None declared, Rocío Paz González: None declared, Valentina Calamia: None declared, Lucía Lourido: None declared, Cristina Ruiz-Romero: None declared, Francisco J. Blanco Grant/research support from: Sanofi-Aventis, Lilly, Bristol MS, Amgen, Pfizer, Abbvie, TRB Chemedica International, Glaxo SmithKline, Archigen Biotech Limited, Novartis, Nichi-iko pharmaceutical Co, Genentech, Jannsen Research \& Development, UCB Biopharma, Centrexion Theurapeutics, Celgene, Roche, Regeneron Pharmaceuticals Inc, Biohope, Corbus Pharmaceutical, Tedec Meiji Pharma, Kiniksa Pharmaceuticals, Ltd, Gilead Sciences Inc, Consultant of: Lilly, Bristol MS, Pfizer

DOI: 10.1136/annrheumdis-2020-eular.4450

\begin{tabular}{|l|l|}
\hline FRI0388 & ARE WE OVERLOOKING OSTEOARTHRITIS? \\
& - A COMPARATIVE STUDY OF PAIN, FUNCTION \\
& AND QUALIFY OF LIFE IN PATIENTS WITH HAND \\
& OSTEOARTHRITIS AND RHEUMATOID ARTHRITIS
\end{tabular}

D. Almeida ${ }^{1,2}$, E. Costa ${ }^{1}$, F. Guimarães ${ }^{2}$, S. Azevedo ${ }^{2}$, J. Rodrigues $^{2}$, J. Silva $^{2}$, D. Faria ${ }^{2}$, F. Teixeira ${ }^{2}$, C. Afonso ${ }^{2}$, J. Tavares-Costa ${ }^{2}$, J. Neves ${ }^{1}$, A. R. Ribeiro ${ }^{1}$ 